IZA DP No. 6603

Dynamics of Disability and Work in Canada

Umut Oguzoglu

May 2012 


\title{
Dynamics of Disability and Work in Canada
}

\author{
Umut Oguzoglu \\ University of Manitoba \\ and IZA
}

\author{
Discussion Paper No. 6603 \\ May 2012
}

IZA
P.O. Box 7240
53072 Bonn
Germany

Phone: +49-228-3894-0

Fax: +49-228-3894-180

E-mail: iza@iza.org

\begin{abstract}
Any opinions expressed here are those of the author(s) and not those of IZA. Research published in this series may include views on policy, but the institute itself takes no institutional policy positions.

The Institute for the Study of Labor (IZA) in Bonn is a local and virtual international research center and a place of communication between science, politics and business. IZA is an independent nonprofit organization supported by Deutsche Post Foundation. The center is associated with the University of Bonn and offers a stimulating research environment through its international network, workshops and conferences, data service, project support, research visits and doctoral program. IZA engages in (i) original and internationally competitive research in all fields of labor economics, (ii) development of policy concepts, and (iii) dissemination of research results and concepts to the interested public.
\end{abstract}

IZA Discussion Papers often represent preliminary work and are circulated to encourage discussion. Citation of such a paper should account for its provisional character. A revised version may be available directly from the author. 


\section{ABSTRACT \\ Dynamics of Disability and Work in Canada*}

Canadian disability policy has come a long way in the past century. However, in contrast with the evidence that disability is not permanent for most, current disability support programs still carry the old static view of permanent disability. By employing a dynamic panel data model of labour force participation, the findings of this paper suggest that labour force exposure is crucial for better return-to-work outcomes for persons with a disability. Without labour force exposure, the effect of a temporary disability is prolonged and participation efforts of the disabled community are slowed down.

JEL Classification: J14, J21, C23

Keywords: disability, labour force participation, dynamic panel data models

Corresponding author:

Umut Oguzoglu

University of Manitoba

Department of Economics

647 Fletcher Argue Bld.

Winnipeg MB.

Canada

E-mail: oguzoglu@cc.umanitoba.ca

\footnotetext{
* The author is grateful to Julia Witt and Wayne Simpson for valuable comments and Jing Han for excellent research assistance. Statistics Canada Disclaimer : This data product is provided 'as-is,' and Statistics Canada makes no warranty, either express or implied, including but not limited to, warranties of merchantability and fitness for a particular purpose. In no event will Statistics Canada be liable for any direct, special, indirect, consequential or other damages, however caused.
} 


\section{Introduction}

Recent reports show that despite qualifications for and desire to work working age Canadians with disabilities have significantly lower labour force participation (HRSDC, 2010). What is more puzzling is that these individuals will continue to have lower labour market involvement even after they recover from their health conditions. Longitudinal evidence suggests that (Kapteyn et al (2008), Galarneau and Ridulescu (2009), Oguzoglu (2010)), for most, disability is temporary and therefore return-to-work should be attainable. However, this is not often the case. Using the Survey of Income and Labour Dynamics (SLID), Galarneau and Ridulescu (2009) report that previously disabled but currently healthy individuals report lower earnings and working hours than those with no previous episode of disability. Charles (2003) and Mok et al (2010) report similar persistent disability effects using US data. In this paper, a dynamic labour force participation model is employed to explain the source of this persistent effect.

The results show that the long lasting adverse effect is partly due to strong state dependence in employment behaviour. That is, lack of labour market exposure during the disability episode has an adverse effect on labour force participation over and above the immediate effect of disability. Moreover, strong state dependence in labour force behaviour causes the temporary disability to affect labour force participation for multiple periods.

The empirical strategy is to model the dynamic relationship between labour force participation and disability with a dynamic panel data model of labour force participation by controlling for state dependence, unobserved heterogeneity and endogeneity of self-assessed disability. I use a longitudinal sample of working age men and women drawn from the first 8 cycles of the National Population Health Survey. 
The paper makes several contributions. First, unlike earlier papers that are based on cross-sectional analyses, a significant justification bias is reported. Second, estimation results and model simulations suggest that static models underestimate the overall effect of disability. Third, policy simulations support policies that incentivise labour force exposure for the disabled.

The paper is organised as follows: Section 2 briefly reviews existing Canadian literature; section 3 provides an overview of the data and presents descriptive statistics; section 4 introduces the multivariate methodology; section 5 reports the estimation results and provides policy simulations; and section 6 concludes.

\section{Recent Canadian Literature}

The recent push towards evidence-based disability policy in Canada is in direct contrast with the scarce Canadian research on this topic, the majority of which is devoted to the identification of work disincentives created by disability support policies (Harkness (1993); Maki (1993); Gruber (2000); Campolieti (2001)). Papers that examine the impact of disability on employment of Canadians are rare and often rely on cross-sectional evidence ${ }^{1}$. Using the Labour Market Activity Survey, Hum and Simpson (1996) report a negative association between disability and various employment outcomes such as annual earnings and working hours. Using the first cycle of the National Population Health Survey (NPHS), Campolieti (2002) shows that disability contributes significantly to labour force participation decisions of older men. However, since cross-sectional surveys are a snap shot in time, these studies may not fully capture the dynamic relationship between disability and labour force status: both potentially time varying characteristics. Although their focus is not on disability, one notable exception is Au et al (2006), who use a static panel data model to investigate the role of health in retirement decisions. Using longitudinal data from NPHS, Au et al. (2005) show that ignoring unobserved heterogeneity can exaggerate the effect of

\footnotetext{
${ }^{1}$ Another important omission from the disability literature is the role of disability on employment of Canadian women. This paper addresses that aspect.
} 
general health status on employment. The authors also address the subjectivity of the health measure in the NPHS with a two-step method that is adapted in this paper and is explained in detail in section 4.

\section{DATA}

The data is drawn from the Canadian National Population Health Survey (NPHS). The NPHS is a nationally representative longitudinal survey that is collected bi-annually by Statistics Canada. The main focus of the NPHS is health outcomes and utilisation of health services; therefore it contains very detailed information on health and health service utilization. Another novel feature of the NPHS is that it includes an objective health Utility Index Mark 3 (HUI3), which combines various details on health to construct a continuous health index. Some demographic and employment related characteristics are also provided, although these are much less detailed than what is available in surveys that specifically collect labourrelated information, such as the Survey of Labour and Income Dynamics (SLID). Additionally, the sample size in the NHPS is much smaller than that of the SLID (Buckley et al. , 2006).

The sample in this paper is drawn from the first 8 cycles (1994/95-2007/08) of the NPHS. It contains an unbalanced sample of 2847 men and 3551 women aged 24 to 64 . The sample contains 18,614 and 23,505 year-person observation for men and women, respectively. Table 1 summarises the demographic characteristics of the sample.

\subsection{Self-Assessed Disability}

Disability is identified according to the following activity limitation question in the NPHS:

"Because of a long term physical or mental health condition, are you limited in the kind or amount of activity you can do at home/school or work?" 
This is the information used in Campolieti $(2002)^{2}$. The subjective nature of this survey question drew much criticism in the literature (Bound et al, 1995). The two main problems are (i) justification bias (people can use disability to rationalize their lack of success in the labour market); and (ii) measurement error (an individual's own self-assessment may not be comparable with other individuals' own selfassessments). Moreover, true health is also potentially endogenous to labour force outcomes since employment can affect health positively (self-confidence, physical activity larger financial resources) or negatively (work injuries, work related stress). Section 4 presents a commonly applied technique to address these problems.

\subsection{Characteristics of the Sample}

Table 2 provides a subset of the demographic information broken down by disability status and gender. It is evident that disability is associated with lower labour force participation for both men and women. The labour force participation rate for men without a disability is 93.6 percent, and only 71 percent for men with a disability. For women, the rates are 69 percent and 60 percent, for women without a disability and disabled women, respectively. Compared to persons without a disability disabled persons have higher prevalence of specific health conditions, have lower HUI3 scores and more likely to be out of normal BMI range. They also tend to be older, less educated and less likely to be a recent immigrant. There are no noticeable regional differences between disabled and not disabled persons.

Table 3 presents the transition across disability and labor force status. Labour force participation is highly persistent; 91 percent of women and 95.5 percent of men remain in the labour force for two consecutive periods. Disability is also persistent, however much less than labour force participation. 70 percent of individuals who are disabled at time $t$ report a disability again in the next period. Table 4 summarises the

\footnotetext{
${ }^{2}$ Activity limitation is more general than survey questions that specifically target the role of disability on paid work (the 'work limitation' question, which is absent from the NPHS). However, there is evidence that the work limitation and the activity limitation measures produce very similar employment effects when they are instrumented by the same set of health conditions (Oguzoglu, 2012).
} 
pattern of disability reports across the entire time period that the sample covers. There is strong evidence against the view that disability is a permanent trait. Only a small portion of individuals report a disability in all cycles, and the majority of disabled individuals report a disability irregularly ${ }^{3}$.

The time varying nature of disability and labour force participation necessitates longitudinal modelling, which is undertaken in the following section.

\section{Multivariate Model and Estimation Strategy}

In this section, details of the dynamic panel data model are described. Dynamic labour force models have two main advantages over static models. First, controlling for lagged employment status avoids a major threat to identification, which is the persistence in employment behaviour masking the real impact of disability. For example, a disabled person's failure in the search for jobs may be due to previous search failures rather than to the disabling conditions themselves (Gannon, 2006). Second, dynamic labour force models provide a channel through which current disability can affect future employment. In other words, being disabled in the current period makes an individual less likely to participate in the labour force and being out of the work force makes an individual less likely to be a participant in the future (Oguzoglu (2010)).

Labour force participation of individual $i$ at time $t$ can be written as follows:

$$
\begin{gathered}
y_{i t}^{*}=\gamma y_{i t-1}+\beta X_{i t}+\delta_{0} D_{i t}^{*}+\delta_{1} D_{i t-1}^{*}+\alpha_{i}+\epsilon_{i t} \\
\epsilon_{i t} \sim N\left(0, \sigma_{i t}\right)
\end{gathered}
$$

where $y_{i t}^{*}$ is the latent labour force status of individual $i$ at time $t . X_{i t}$ are demographic characteristics. $\mathrm{D}_{\mathrm{it}}{ }^{*}$ and $\mathrm{D}_{\mathrm{it}-1}{ }^{*}$ are current and past true disability status that are unknown to the researcher. Instead of true disability we observe self-assessed disability $(\mathrm{SAD})$, which is an imperfect proxy of $\mathrm{D}_{\mathrm{it}}{ }^{*}$. The relationship between $\mathrm{SAD}$ and $\mathrm{D}_{\mathrm{it}}$ can be formulated as follows:

\footnotetext{
${ }^{3}$ Small changes in the sampling windows did not change this result significantly.
} 


$$
\mathrm{SAD}_{\mathrm{it}}=\mathrm{D}_{\mathrm{it}}^{*}+\eta_{\mathrm{it}}(2)
$$

If $E\left[\eta_{i t}, \epsilon_{i t}\right]=0$, model (1) underestimates the true effect of disability due to the measurement error. If, on the other hand, $\mathrm{E}\left[\eta_{\mathrm{it}}, \epsilon_{\mathrm{it}}\right]<0$, this leads to an overestimate of $\delta_{0}$ and $\delta_{1}$ due to justification bias, and an underestimate of $\delta_{0}$ and $\delta_{1}$ due to the measurement error. One solution to this type of endogeneity is to use an instrumental variable approach. Assume that disability is self-reported according to the following $\operatorname{model}^{4}$

$$
S A D_{i t}=\beta Z_{i t}+v_{i}+u_{i t}(3)
$$

where, $\mathrm{Z}_{\mathrm{it}}$ contains a sub-set of $\mathrm{X}_{\mathrm{it}}$ plus specific health characteristics. I assume that time varying errors $\epsilon_{i t}, \eta_{i t}$, and $u_{i t}$ are uncorrelated. The unobserved heterogeneity in (1) and (3) are modeled as random effects with $\alpha_{i} \sim N\left(0, \sigma_{\alpha}\right)$ and $v_{i} \sim N\left(0, \sigma_{v}\right)$. One caveat of the random effects specification is that unobserved individual specific heterogeneity has to be assumed to be uncorrelated with the observed characteristics included in the model. In order to relax this assumption, time averages of all control variables in $\mathrm{X}_{\mathrm{it}}$ are added to (1) as in Mundlak (1978), similarly time averages of all time varying variables in $\mathrm{Z}_{\mathrm{it}}$ are added to (3). The empirical strategy is to replace $\mathrm{D}_{\mathrm{it}}{ }^{*}$ in (1) with the predicted linear index of (3) as in Au et al (2006).

An important issue regarding the estimation of dynamic nonlinear models is the initial conditions problem (Heckman, 1981). The problem is that initial realisations of labour force participation and disability status, which are unobserved for the majority of individuals in the data, have a crucial impact on the entire path of outcomes. Treating initial conditions as exogenous produces heavily biased estimates. I

\footnotetext{
${ }^{4}$ When a dynamic version of the disability regression is estimated the impact on the predicted index was not significant.
} 
use an approach suggested by Wooldridge (2005), which is to include the dependent variable from the first wave as an additional regressor in $(1)^{5}$.

\section{RESULTS}

In this section estimation results from the labour force models are reported. Various versions of model (1) are considered. In Table 5, model estimates from the dynamic model (1) are presented for men and women. Columns 1 and 3 report estimates from the models that use the raw self-assessed disability. Columns 2 and 4 report estimates of the models that use the endogeneity correction ${ }^{6}$. The estimations are repeated for the static version of model (1) where the feedback effect of lagged labour force participation is ignored. These results are reported in Table 6.

It is evident that current and past disabilities have a significant adverse impact on labour force participation. The significance is robust to dynamic specification and endogeneity correction. Dynamic models suggest that there is strong state dependence in labour force behaviour. Independent of disability status or other demographic controls, individuals who were labour force participants in the past are more like to be current labour force participants.

The results have two implications, both of which emphasize the role of labour market exposure. First, since past labour force participation increases the current likelihood of participation, increasing labour force participation of people at risk of being disabled (or of those who are disabled) is crucial. Secondly, since not being in the labour force is as detrimental to future participation as being disabled, policies that incentivise labour force participation for the disabled may produce positive return-to-work outcomes for disabled persons.

\footnotetext{
${ }^{5}$ Another possibility is to follow Heckman (1981) and approximate the initial conditions with a static probit model using data from the first observed period. This static model than can be jointly estimated with the dynamic models (1) using FIML. This technique is computationally more demanding and cannot be implemented with standard software such as STATA.

${ }^{6}$ The instrument set that is for the correction is specific health conditions in the first stage regression as instruments (see Table 8). Another version of the correction -not reported here- uses HUI3 as an instrument. The average partial effect of disability from all models is provided in Table 7.
} 
The effect of demographic characteristics can be briefly summarised as follows: Labour force participation is increasing in age with a decreasing rate. Being married increases the likelihood of participation for men but not for women, the number of dependent children decreases labour force participation. Immigrant men are more likely to be in the labour force than Canadian born men, while immigrant women are more likely to be out of the work force than Canadian born women. Higher education increased the likelihood of participation.

\section{Average Partial Effects}

Since Model (1) is nonlinear, the coefficients provided in Tables 5 and 6 have no meaning except for their sign and significance. Following Wooldridge (2005), Average Partial Effects (APEs) of current disability are calculated. The APEs provided in Table 7 represent the percentage change in the likelihood of labour force participation due to disability. All variables other than disability are set to their gender specific sample means, and random effects are set to zero. The second column of Table 7 (labelled SAD) contains the APEs of disability according to models that use raw self-assessed disability. The third and fourth columns report APEs estimated by models with the endogeneity correction. The Disability Index refers to endogeneity correction that use detailed health information as instruments. In the HUI3 model, the HUI3 index is the instrument.

From Table 7, it is apparent that the SAD model overestimates the immediate effect of disability for men and -to a much smaller degree- for women. The significant justification bias reported here contradicts earlier findings based on a cross sectional sample of older men from NPHS (Campolieti, 2002). Larger differences for men compared to women, between the SAD and the endogeneity corrected models are consistent with earlier findings using Australian panel data (Cai, 2010). This gender difference may indicate that men, for whom non-work may be less socially acceptable than for women, tend to overreport disability to justify labour market failures. Regardless, the average effect of disability is substantial and, for men, is comparable to earlier cross-sectional estimates (Campolieti, 2002). However, as 
following section will demonstrate, the APE measures only the immediate effect of disability. Therefore, overall effect of disability on labour force participation can be significantly underestimated by the cross sectional and static panel data models.

\subsection{Model Simulations}

High persistence in labour force participation may operate as a feedback channel through which the disability shock can influence participation for multiple periods. By ignoring this, static models underestimate the full impact of disability since the overall effect of disability can, in fact, be much larger than the immediate impact suggested by the APEs. In order to illustrate this, I use the endogeneity corrected models with dynamic and static specifications and simulate the effect of a temporary disability. The details of the simulation are as follows: The disability shock is introduced in period $t=1$. Individuals, who are given the average characteristics of the sample, are assumed to be not disabled before and after the shock. Figure 1 presents results of the simulation for men and women

As expected, the Static model predicts a much quicker recovery. Note that the lagged disability variable that is included for both models captures some of the feedback effect for the static model. Nevertheless, a temporary disability in period 1 has no effect after period 3. The dynamic models, however, show that the full impact of a temporary disability takes up to four periods to be fully realised. This is purely due to the feedback effect that is captured by the lagged labour force status. Figure 1 helps to understand the findings of Galernaeu and Ridelescu (2009). Past disability has a lingering effect on labour force participation -hence earnings - due to the dynamic nature of labour force behaviour. Lower labour force exposure in the past (due to past disability) lowers the likelihood of participation in the future.

\section{Policy Simulations: Cases of Temporary and Permanent Disability}

Findings from the previous sections imply that disability can have a long lasting effect on labour force participation due to the feedback effect coming from the lagged labour force participation status. This 
suggests that policies that encourage labour force participation during an episode of disability (such as training, part time work, alternative employment) may shorten the recovery period.

In order to assess this possibility, I simulate the effect of a policy that incentivises labour force participation for those who drop out of the labour force due to disability. The details of the simulation are as follows: using the dynamic model estimates with the endogeneity correction, labour force participation of an individual with average -gender specific- characteristics of a disabled person is simulated. Initially, at $t=0$, the individual is assumed to be not-disabled. Two patterns of disability are considered; $a$ temporary disability which refers to the case where individual becomes disabled at $t=1$ and recovers immediately, and a permanent disability which refers to the case where the individuals becomes disabled at $t=1$ and stays disabled in the following periods. The simulated policy incentivizes labour force participation for those who drop out of the labour force due to disability. The policy comes into effect at the same time that the individual becomes disabled $(t=1)$ and lasts only one period.

Figure 2 plots the simulated paths after a temporary disability. Labour force response for men and women with and without the policy are reported. I allow the lagged disability to affect the participation for both policy and no policy cases. Without the policy, the immediate impact of the disability is very dramatic. A man with the average characteristics of the disabled sample is 6 percent less likely to participate in the labour force due to a disability. It is evident that the strong state dependence of labour force behaviour prolongs the positive effect of a one-period policy. At $t=2$, individuals that were covered by the policy are still around 2 percent more likely to be in the labour force compared to individuals who were not covered by the policy. The temporary policy does not have a permanent effect. At $t=3$, the policy has only half of a percentage point effect and by period 4 there is no significant difference between paths with and without policy.

I repeat the identical policy simulation for a permanently disabled person. Once again the policy, which incentivises labour force participation, lasts only one period. The permanent disability is simulated by 
introducing the disability shock repeatedly every period. As before, the policy does not have a permanent impact, however the policy's positive impact lasts beyond the periods that the policy was in effect.

\section{CONCLUSION}

In this paper the impact of disability is estimated using a dynamic panel data model of labour force participation. Endogeneity of self-assessed disability is addressed by using detailed health outcomes as instruments. The results are consistent with the earlier works that use data from the US, Ireland and Australia by showing that labour force behaviour is highly persistent and disability -for most - is

temporary. The role of state dependence in amplifying the effect of disability is a feature hidden from the static models, and this hidden feature may explain why currently healthy individuals are still suffering from disability episodes from the past.

In some sense, policy simulations justify the critics of an active disability employment policy. Since there is no permanent impact, temporary interventions are bound to fail and repeated interventions such as permanent wage subsidies, similar to policies pursued in Denmark, are costly (OECD,2010). However, it is also shown that the positive impact of the policy outlasts the period that the policy is in effect. For individuals who were temporarily disabled (for example, those with temporary back injuries), policies that incentivise labour force participation greatly reduce the recovery period or remove the impact of disability entirely by eliminating the feedback effect of lagged non-participation. In this context, recent changes in Disability Support Pension in Australia, which require moderately disabled to be involved in a work activity (working or looking for work or training), may provide a useful blueprint for successful policy.

For the permanently disabled, it was obvious from the results of this paper that greater participation requires permanent interventions. No doubt, wage subsidies of this kind would be very costly. However, not all permanently effective policies are associated with repeated financial cost. Investments in work environments to accommodate people with disabilities would have a permanent effect without repeated 
cost to tax payers. Similarly, investments in human capital in the form of training or re-training would provide permanently positive effects.

In Canada, disabled individuals gained much ground in the past century in terms of social and economic participation. Yet, Canada still lags behind other Western democracies because there is no national comprehensive disability policy (Jongbloed, 2003). The finding of this paper suggest that Canadians with a disability can benefit from more active employment policies to supplement recent positive changes, namely the Working Tax Credit and the Disability Savings Account. 
TABLE 1: MEAN OF THE VARIABLED USED IN THE ANALYSIS

\begin{tabular}{|c|c|c|c|}
\hline VARIABLE NAME & DEFINITION & MEN & WOMEN \\
\hline Inlf & $=1$ if in labour force & 0.89 & 0.76 \\
\hline Acli & $=1$ if disabled & 0.19 & 0.20 \\
\hline resp & $=1$ if respiratory problems & 0.07 & 0.09 \\
\hline arth & $=1$ if has arthritis & 0.11 & 0.17 \\
\hline bapr & $=1$ if has back problems excluding arthritis & 0.16 & 0.17 \\
\hline blpr & $=1$ if has high blood pressure & 0.10 & 0.11 \\
\hline mig & $=1$ if has migraine & 0.05 & 0.15 \\
\hline diab & $=1$ if has diabetes & 0.04 & 0.03 \\
\hline hecon & $=1$ if has heart condition & 0.03 & 0.02 \\
\hline cancer & $=1$ if has cancer & 0.01 & 0.02 \\
\hline vipro & $=1$ if has vision problems & 0.01 & 0.02 \\
\hline othercond & $=1$ has other health condition & 0.18 & 0.19 \\
\hline BMI2034 & $=1$ if $\mathrm{BMI}$ is less than 20 or more than 34 & 0.08 & 0.21 \\
\hline age & $\mathrm{AGE} / 10$ & 4.31 & 4.30 \\
\hline age 2 & $\mathrm{AGE}^{2} / 100$ & 19.81 & 19.72 \\
\hline housesize1 & $=1$ if house size $=1$ & 0.13 & 0.10 \\
\hline housesize2 & $=1$ if house size $=2$ & 0.28 & 0.31 \\
\hline housesize 3 & $=1$ if house size $=3$ & 0.20 & 0.23 \\
\hline housesize4 & $=1$ if house size $=4$ & 0.24 & 0.22 \\
\hline Housesize 5 & $=1$ if house size $>4$ & 0.15 & 0.14 \\
\hline capincome & $=1$ if has capital income & 0.21 & 0.20 \\
\hline ownhouse & $=1$ if own house & 0.76 & 0.74 \\
\hline marr & $=1$ if married & 0.62 & 0.61 \\
\hline numkids & Number of children & 0.50 & 0.53 \\
\hline nohischool & $=1$ if no high school diploma & 0.03 & 0.03 \\
\hline highschool & $=1$ if highest diploma is high school & 0.13 & 0.16 \\
\hline sopostsec & $=1$ if highest education is post secondary & 0.27 & 0.27 \\
\hline univerdegree & $=1$ if highest education is university or higher & 0.44 & 0.43 \\
\hline white & $=1$ if white & 0.50 & 0.50 \\
\hline immig & $=1$ if immigrant & 0.18 & 0.18 \\
\hline QUEBEC & $=1$ if resides in Quebec & 0.26 & 0.25 \\
\hline PRIARIE & $=1$ if resides in $\mathrm{ALB}, \mathrm{MB}$ or SASK & 0.17 & 0.17 \\
\hline $\mathrm{ON}$ & $=1$ if resides in Ontario & 0.37 & 0.37 \\
\hline $\mathrm{BC}$ & $=1$ if resides in $\mathrm{BC}$ & 0.12 & 0.13 \\
\hline EAST & $=1$ if resides in NB, PEI, NF & 0.05 & 0.05 \\
\hline
\end{tabular}

Note : Statistics are calculated using a pooled sample of all 8 cycles of NPHS. 


\begin{tabular}{|c|c|c|c|c|}
\hline & \multicolumn{2}{|c|}{ MEN } & \multicolumn{2}{|c|}{ WOMEN } \\
\hline & DISABLED & NOT DISABLED & DISABLED & NOT DISABLED \\
\hline Labour Force Participation & 71.13 & 93.64 & 60.38 & 69.38 \\
\hline \multicolumn{5}{|l|}{ Health } \\
\hline HUI3 & 0.75 & 0.94 & 0.72 & 0.93 \\
\hline resp & 0.11 & 0.06 & 0.17 & 0.07 \\
\hline arth & 0.31 & 0.07 & 0.43 & 0.11 \\
\hline bapr & 0.37 & 0.11 & 0.39 & 0.11 \\
\hline blpr & 0.19 & 0.08 & 0.18 & 0.09 \\
\hline mig & 0.09 & 0.04 & 0.23 & 0.13 \\
\hline diab & 0.09 & 0.03 & 0.06 & 0.02 \\
\hline hecon & 0.10 & 0.02 & 0.07 & 0.01 \\
\hline cancer & 0.03 & 0.00 & 0.03 & 0.01 \\
\hline vipro & 0.04 & 0.01 & 0.05 & 0.01 \\
\hline othercond & 0.12 & 0.20 & 0.12 & 0.21 \\
\hline BMI2034 & 0.12 & 0.07 & 0.25 & 0.20 \\
\hline \multicolumn{5}{|l|}{ Other characteristics } \\
\hline Age & 4.64 & 4.24 & 4.62 & 4.22 \\
\hline age 2 & 22.72 & 19.13 & 22.56 & 19.00 \\
\hline housesize1 & 0.15 & 0.13 & 0.15 & 0.09 \\
\hline housesize2 & 0.32 & 0.27 & 0.37 & 0.30 \\
\hline housesize3 & 0.19 & 0.21 & 0.22 & 0.23 \\
\hline housesize4 & 0.21 & 0.24 & 0.16 & 0.24 \\
\hline Housesize 5 & 0.13 & 0.15 & 0.10 & 0.14 \\
\hline capincome & 0.20 & 0.21 & 0.20 & 0.19 \\
\hline ownhouse & 0.74 & 0.76 & 0.72 & 0.75 \\
\hline marr & 0.62 & 0.62 & 0.56 & 0.62 \\
\hline numkids & 0.39 & 0.53 & 0.34 & 0.58 \\
\hline nohischool & 0.06 & 0.02 & 0.05 & 0.03 \\
\hline highschool & 0.13 & 0.13 & 0.14 & 0.16 \\
\hline sopostsec & 0.28 & 0.26 & 0.30 & 0.26 \\
\hline univerdegree & 0.38 & 0.46 & 0.38 & 0.44 \\
\hline white & 0.46 & 0.51 & 0.48 & 0.50 \\
\hline immig & 0.14 & 0.18 & 0.14 & 0.19 \\
\hline quebec & 0.24 & 0.27 & 0.20 & 0.27 \\
\hline PRARIE & 0.18 & 0.16 & 0.18 & 0.16 \\
\hline $\mathrm{ON}$ & 0.38 & 0.37 & 0.37 & 0.37 \\
\hline $\mathrm{BC}$ & 0.11 & 0.12 & 0.15 & 0.12 \\
\hline EAST & 0.05 & 0.05 & 0.05 & 0.05 \\
\hline
\end{tabular}

Note : Statistics are calculated using a pooled sample of all 8 cycles of NPHS. 


\begin{tabular}{rcc} 
& \multicolumn{2}{c}{ Disabled at $t$} \\
Disabled at $t-1$ & MEN & WOMEN \\
& 70.51 & 70.24 \\
& Labour Force Participant at $t$ \\
Labour Force Participant at $t-1$ & MEN & WOMEN \\
& 95.47 & 91.72
\end{tabular}

Note : Statistics are calculated using a pooled sample of all 8 cycles of NPHS.

TABLE 4: DISABILITY REPORTING PATTERNS \& LABOUR FORCE PARTICIPATION

\begin{tabular}{cccc}
\hline & Always Disabled & Never Disabled & Irregular Disabled \\
MEN & 4.09 & 56.88 & 39.04 \\
LF Participant & 57.09 & 97.07 & 91.9 \\
& & & 42.2 \\
WOMEN & 3.97 & 53.82 & 83.06 \\
LF Participant & 58.21 & 85.51 & \\
\hline
\end{tabular}

Note: Statistics are calculated using a pooled sample of all 8 cycles of NPHS. 
TABLE 5: DYNAMIC LABOUR FORCE MODEL ESTIMATES

\begin{tabular}{|c|c|c|c|c|}
\hline \multirow[b]{2}{*}{ Disability Measure: } & \multicolumn{2}{|c|}{ Men } & \multicolumn{2}{|c|}{ Women } \\
\hline & SAD & Disability Index & SAD & Disability Index \\
\hline \multirow[t]{2}{*}{$\mathrm{LF}_{\mathrm{t}-1}$} & $1.347^{* * * *}$ & $1.367^{* * *}$ & $1.347^{* * *}$ & $1.232^{* * * *}$ \\
\hline & $(0.0022)$ & $(0.0016)$ & $(0.0013)$ & $(0.0010)$ \\
\hline \multirow[t]{2}{*}{ Initial LF } & $0.726^{* * *}$ & $0.869^{* * *}$ & $0.707^{* * *}$ & $0.725^{* * *}$ \\
\hline & $(0.0033)$ & $(0.0025)$ & $(0.0017)$ & $(0.0013)$ \\
\hline \multirow{2}{*}{ Disabled $_{t}$} & $-0.765^{* * *}$ & $-0.284^{* * *}$ & $-0.404^{* * *}$ & $-0.185^{* * *}$ \\
\hline & $(0.0018)$ & $(0.0008)$ & $(0.0013)$ & $(0.0007)$ \\
\hline \multirow[t]{2}{*}{ Disabled $_{t-1}$} & $-0.358^{* * * *}$ & $-0.115^{* * * *}$ & $-0.0950^{* * *}$ & $-0.0732^{* * * *}$ \\
\hline & $(0.0018)$ & $(0.0009)$ & $(0.0014)$ & $(0.0007)$ \\
\hline \multirow[t]{2}{*}{ age } & $2.357^{* * *}$ & $1.858^{* * *}$ & $1.857^{* * *}$ & $1.939^{* * *}$ \\
\hline & $(0.0153)$ & $(0.0079)$ & $(0.0117)$ & $(0.0057)$ \\
\hline \multirow[t]{2}{*}{ age2 } & $-0.275^{* * * *}$ & $-0.270^{* * * *}$ & $-0.315^{* * *}$ & $-0.271^{\text {***** }}$ \\
\hline & $(0.0012)$ & $(0.0008)$ & $(0.0008)$ & $(0.0006)$ \\
\hline \multirow[t]{2}{*}{ housesize1 } & $0.0399^{* * *}$ & $0.0913^{* * *}$ & 0.00 & $0.0237^{* * *}$ \\
\hline & $(0.0037)$ & $(0.0025)$ & $(0.0029)$ & $(0.0021)$ \\
\hline \multirow[t]{2}{*}{ housesize2 } & $-0.136^{* * *}$ & $0.0870^{* * *}$ & $-0.0873^{* * *}$ & $0.0168^{* * *}$ \\
\hline & $(0.0031)$ & $(0.0021)$ & $(0.0021)$ & $(0.0016)$ \\
\hline \multirow[t]{2}{*}{ housesize3 } & $-0.0390^{* * * *}$ & $0.170^{* * * *}$ & $-0.0654^{* * *}$ & $0.0227^{* * * *}$ \\
\hline & $(0.0030)$ & $(0.0021)$ & $(0.0019)$ & $(0.0015)$ \\
\hline \multirow[t]{2}{*}{ housesize4 } & $0.174^{* * *}$ & $0.258^{* * *}$ & $-0.0652^{* * * *}$ & $0.0221^{* * * * *}$ \\
\hline & $(0.0028)$ & $(0.0020)$ & $(0.0017)$ & $(0.0013)$ \\
\hline \multirow[t]{2}{*}{ capincome } & $0.0317^{* * * *}$ & $-0.0662^{* * *}$ & $-0.0885^{* * *}$ & $-0.0684^{* * * *}$ \\
\hline & $(0.0019)$ & $(0.0013)$ & $(0.0013)$ & $(0.0011)$ \\
\hline \multirow[t]{2}{*}{ ownhouse } & $-0.00684^{*}$ & $0.00849^{* * *}$ & $-0.105^{* * * *}$ & $-0.00768^{* * * *}$ \\
\hline & $(0.0028)$ & $(0.0021)$ & $(0.0021)$ & $(0.0016)$ \\
\hline \multirow[t]{2}{*}{ marr } & $0.276^{* * *}$ & $0.238^{* * *}$ & $-0.268^{* * *}$ & $-0.307^{* * *}$ \\
\hline & $(0.0034)$ & $(0.0026)$ & $(0.0022)$ & $(0.0017)$ \\
\hline \multirow[t]{2}{*}{ numkids } & $-0.0810^{* * * *}$ & $-0.116^{* * *}$ & $-0.206^{* * *}$ & $-0.261^{* * * *}$ \\
\hline & $(0.0013)$ & $(0.0010)$ & $(0.0009)$ & $(0.0007)$ \\
\hline \multirow[t]{2}{*}{ highschool } & $0.434^{* * * *}$ & $0.280^{* * * *}$ & $0.328^{* * * *}$ & $0.164^{* * * *}$ \\
\hline & $(0.0030)$ & $(0.0020)$ & $(0.0020)$ & $(0.0015)$ \\
\hline \multirow[t]{2}{*}{ sopostsec } & $0.264^{* * *}$ & $0.147^{* * *}$ & $0.253^{* * *}$ & $0.212^{* * *}$ \\
\hline & $(0.0024)$ & $(0.0016)$ & $(0.0019)$ & $(0.0014)$ \\
\hline \multirow[t]{2}{*}{ univerdegree } & $0.407^{* * *}$ & $0.402^{* * *}$ & $0.489^{* * *}$ & $0.426^{* * *}$ \\
\hline & $(0.0024)$ & $(0.0015)$ & $(0.0018)$ & $(0.0013)$ \\
\hline \multirow[t]{2}{*}{ white } & $-0.171^{* * * *}$ & $0.0482^{* * * *}$ & $0.155^{* * *}$ & $0.200^{* * * *}$ \\
\hline & $(0.0041)$ & $(0.0024)$ & $(0.0024)$ & $(0.0018)$ \\
\hline \multirow[t]{2}{*}{ immig } & $0.0615^{* * * *}$ & $-0.0383^{* * * *}$ & $0.0383^{* * *}$ & $-0.0977^{* * * *}$ \\
\hline & $(0.0023)$ & $(0.0016)$ & $(0.0016)$ & $(0.0013)$ \\
\hline \multirow[t]{2}{*}{ PRARIE } & $0.372^{* * *}$ & $0.430^{* * *}$ & $0.111^{* * *}$ & $0.218^{* * *}$ \\
\hline & $(0.0026)$ & $(0.0018)$ & $(0.0017)$ & $(0.0014)$ \\
\hline
\end{tabular}




\begin{tabular}{lcccc}
\hline Table 5 cont. & & & & \\
ON & $0.172^{* * *}$ & $0.297^{* * *}$ & $0.200^{* * * *}$ & $0.319^{* * *}$ \\
& $(0.0020)$ & $(0.0014)$ & $(0.0015)$ & $(0.0012)$ \\
BC & $-0.0781^{* * *}$ & $0.0721^{* * *}$ & $0.167^{* * *}$ & $0.201^{* * *}$ \\
& $(0.0026)$ & $(0.0018)$ & $(0.0019)$ & $(0.0015)$ \\
EAST & 0.01 & $0.0213^{* * *}$ & $-0.120^{* * *}$ & $-0.0359^{* * *}$ \\
& $(0.0035)$ & $(0.0024)$ & $(0.0025)$ & $(0.0020)$ \\
CONST. & $-5.770^{* * *}$ & $-5.076^{* * *}$ & $-6.762^{* * * *}$ & $-6.020^{* * *}$ \\
& $(0.0309)$ & $(0.0122)$ & $(0.0225)$ & $(0.0097)$ \\
$\ln \left(\sigma_{u}\right)$ & $-0.736^{* * *}$ & $-0.673^{* * *}$ & $-0.921^{* * *}$ & $-0.733^{* * *}$ \\
& $(0.0048)$ & $(0.0037)$ & $(0.0034)$ & $(0.0025)$ \\
\hline
\end{tabular}

Note: Standard Errors are in parenthesis. ${ }^{* *{ }^{*},{ }^{* * *}}$ refer to significance at 10,5 and 1 percent respectively. All models include time dummies and the time averages of all time varying control variables. $\mathrm{LF}_{\mathrm{t}-1}$ is the labour force participation from the previous period. Initial LF is the labour force participation status at first cycle. 
TABLE 6: STATIC LABOUR FORCE MODEL ESTIMATES

\begin{tabular}{|c|c|c|c|c|}
\hline & \multicolumn{2}{|c|}{ Men } & \multicolumn{2}{|c|}{ Women } \\
\hline & SAD & Disability Index & SAD & Disability Index \\
\hline \multirow[t]{2}{*}{ Disabled $_{t}$} & $-1.003^{* * *}$ & $-0.394^{* * *}$ & $-0.507^{* * *}$ & $-0.270^{* * *}$ \\
\hline & $(0.0021)$ & $(0.0010)$ & $(0.0015)$ & $(0.0008)$ \\
\hline \multirow{2}{*}{ Disabled $_{t-1}$} & $-0.692^{* * *}$ & $-0.280^{* * *}$ & $-0.315^{* * *}$ & $-0.174^{* * *}$ \\
\hline & $(0.0020)$ & $(0.0010)$ & $(0.0016)$ & (0.0009) \\
\hline \multirow[t]{2}{*}{ age } & $4.095^{* * *}$ & $3.070^{* * *}$ & $2.844^{* * * *}$ & $3.150^{* * *}$ \\
\hline & $(0.0186)$ & $(0.0092)$ & $(0.0157)$ & $(0.0065)$ \\
\hline \multirow[t]{2}{*}{ age 2} & $-0.479^{* * *}$ & $-0.469^{* * *}$ & $-0.497^{* * *}$ & $-0.465^{* * *}$ \\
\hline & $(0.0012)$ & $(0.0008)$ & $(0.0008)$ & $(0.0006)$ \\
\hline \multirow[t]{2}{*}{ housesize1 } & $0.0324^{* * *}$ & 0.01 & $0.138^{* * *}$ & $0.180^{* * *}$ \\
\hline & $(0.0047)$ & $(0.0035)$ & $(0.0036)$ & $(0.0027)$ \\
\hline \multirow[t]{2}{*}{ housesize2 } & $-0.211^{* * *}$ & $-0.0191^{* * *}$ & $0.00998^{* * *}$ & $0.126^{* * *}$ \\
\hline & $(0.0039)$ & $(0.0030)$ & $(0.0026)$ & $(0.0021)$ \\
\hline \multirow[t]{2}{*}{ housesize3 } & $-0.0141^{* * *}$ & $0.109^{* * *}$ & $-0.0243^{* * *}$ & $0.0740^{* * *}$ \\
\hline & $(0.0038)$ & $(0.0029)$ & $(0.0023)$ & $(0.0019)$ \\
\hline \multirow[t]{2}{*}{ housesize4 } & $0.207^{* * *}$ & $0.171^{* * *}$ & $-0.0329^{* * * *}$ & $0.0382^{* * *}$ \\
\hline & $(0.0035)$ & $(0.0028)$ & $(0.0021)$ & $(0.0017)$ \\
\hline \multirow[t]{2}{*}{ capincome } & $0.00441^{*}$ & $-0.0631^{* * *}$ & $-0.103^{* * *}$ & $-0.0930^{* * * *}$ \\
\hline & $(0.0021)$ & $(0.0015)$ & $(0.0014)$ & $(0.0012)$ \\
\hline \multirow[t]{2}{*}{ ownhouse } & $-0.0487^{* * *}$ & $-0.0551^{* * * *}$ & $-0.144^{* * *}$ & $0.0123^{* * *}$ \\
\hline & $(0.0032)$ & $(0.0024)$ & $(0.0023)$ & $(0.0017)$ \\
\hline \multirow[t]{2}{*}{ marr } & $0.445^{* * *}$ & $0.438^{* * *}$ & $-0.431^{* * *}$ & $-0.447^{* * *}$ \\
\hline & $(0.0038)$ & $(0.0031)$ & $(0.0024)$ & $(0.0019)$ \\
\hline \multirow[t]{2}{*}{ numkids } & $-0.0833^{* * *}$ & $-0.153^{* * *}$ & $-0.385^{* * *}$ & $-0.437^{* * *}$ \\
\hline & $(0.0015)$ & $(0.0012)$ & $(0.0009)$ & $(0.0008)$ \\
\hline \multirow[t]{2}{*}{ highschool } & $0.767^{* * *}$ & $0.500^{* * *}$ & $0.688^{* * *}$ & $0.443^{* * *}$ \\
\hline & $(0.0047)$ & $(0.0032)$ & $(0.0033)$ & $(0.0024)$ \\
\hline \multirow[t]{2}{*}{ sopostsec } & $0.470^{* * *}$ & $0.253^{* * *}$ & $0.649^{* * *}$ & $0.575^{* * *}$ \\
\hline & $(0.0037)$ & $(0.0025)$ & $(0.0030)$ & $(0.0021)$ \\
\hline \multirow[t]{2}{*}{ univerdegree } & $0.659^{* * *}$ & $0.648^{* * *}$ & $1.160^{* * * *}$ & $1.029^{* * * *}$ \\
\hline & $(0.0036)$ & $(0.0025)$ & $(0.0030)$ & $(0.0021)$ \\
\hline \multirow[t]{2}{*}{ white } & 0.00 & $0.140^{* * *}$ & $0.167^{* * *}$ & $0.236^{* * *}$ \\
\hline & $(0.0047)$ & $(0.0032)$ & $(0.0028)$ & $(0.0022)$ \\
\hline \multirow[t]{2}{*}{ immig } & $0.101^{* * *}$ & $0.0111^{* * *}$ & $-0.0291^{* * *}$ & $-0.235^{* * *}$ \\
\hline & $(0.0036)$ & $(0.0026)$ & $(0.0027)$ & $(0.0020)$ \\
\hline \multirow[t]{2}{*}{ PRARIE } & $0.614^{* * *}$ & $0.788^{* * *}$ & $0.312^{* * *}$ & $0.451^{* * *}$ \\
\hline & $(0.0040)$ & $(0.0030)$ & $(0.0031)$ & $(0.0023)$ \\
\hline \multirow[t]{2}{*}{$\mathrm{ON}$} & $0.268^{* * *}$ & $0.474^{* * *}$ & $0.389^{* * *}$ & $0.558^{* * *}$ \\
\hline & $(0.0032)$ & $(0.0023)$ & $(0.0025)$ & (0.0019) \\
\hline \multirow[t]{2}{*}{$\mathrm{BC}$} & $-0.0770^{* * *}$ & $0.173^{* * *}$ & $0.313^{* * *}$ & $0.347^{* * *}$ \\
\hline & $(0.0041)$ & $(0.0031)$ & $(0.0034)$ & $(0.0025)$ \\
\hline
\end{tabular}




\begin{tabular}{lcccc}
\hline Table 6 cont. & & & \\
EAST & $-0.0470^{* * *}$ & $-0.0137^{* * *}$ & $-0.121^{* * *}$ & $-0.0278^{* * *}$ \\
& $(0.0055)$ & $(0.0041)$ & $(0.0045)$ & $(0.0033)$ \\
Const. & $-7.581^{* * *}$ & $-6.209^{* * *}$ & $-7.459^{* * *}$ & $-7.778^{* * *}$ \\
& $(0.0475)$ & $(0.0187)$ & $(0.0372)$ & $(0.0147)$ \\
$\ln \left(\sigma_{u}\right)$ & $0.693^{* * *}$ & $0.974^{* * *}$ & $0.783^{* * *}$ & $0.893^{* * *}$ \\
& $(0.0026)$ & $(0.0018)$ & $(0.0017)$ & $(0.0013)$ \\
\hline
\end{tabular}

Note : Standard Errors are in parenthesis. ${ }^{* * * * * *}$ refer to significance at 10,5 and 1 percent respectively. All models include time dummies and the time averages of all time varying control variables.

TABLE 7: AVERAGE PARTIAL EFFECTS OF DISABILITY

STATIC MODELS

\begin{tabular}{rccc} 
& & \multicolumn{2}{c}{ ENDOGENOUS DISABILITY } \\
\cline { 3 - 4 } MEN & $S A D$ & DISAB. INDEX & HUI3 \\
WOMEN & -0.0707 & -0.0364 & -0.0598 \\
& -0.0435 & -0.0469 & -0.051
\end{tabular}

DYNAMIC MODELS

\begin{tabular}{rccc} 
& & \multicolumn{2}{c}{ ENDOGENOUS DISABILITY } \\
\cline { 3 - 4 } MEN & SAD & DISAB. INDEX & HUI3 \\
WOMEN & -0.0812 & -0.0409 & -0.0413 \\
& -0.0532 & -0.0356 & -0.0409 \\
\hline
\end{tabular}

Note: Statics represents the percentage change in likelihood of labour force participation due to disability. All other characteristics of the model are set to their gender specific sample averages. Random Effects are set to zero. SAD is the raw self-assessed disability. Disab. Index use the specific health measure as instruments to create the disability index. HUI3 use HUI3 health index as instruments. 
Figure 1: Labour Force Response: Dynamic vs Static Models

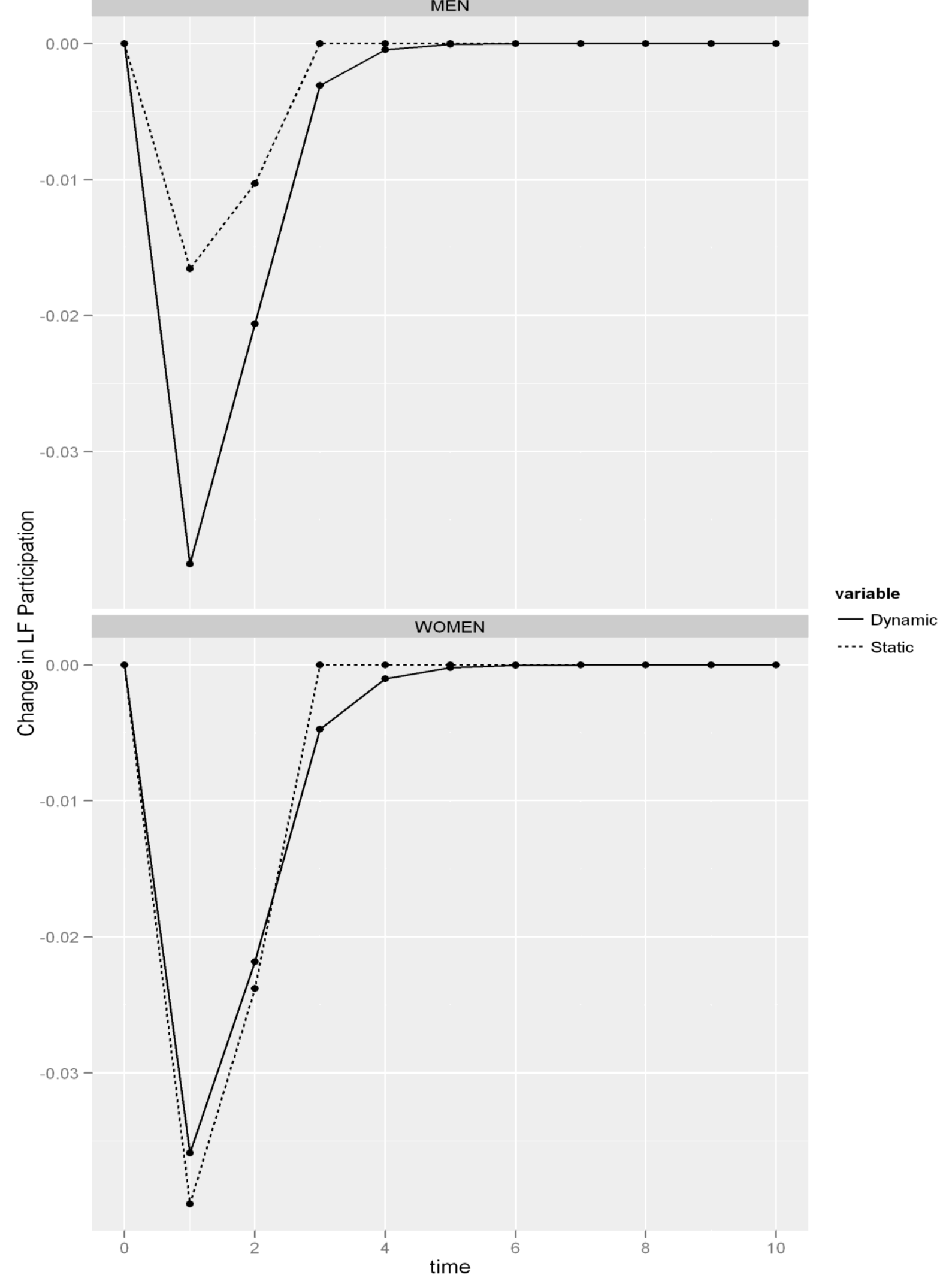


Figure 2 Labour Force Response to a Temporary Disability

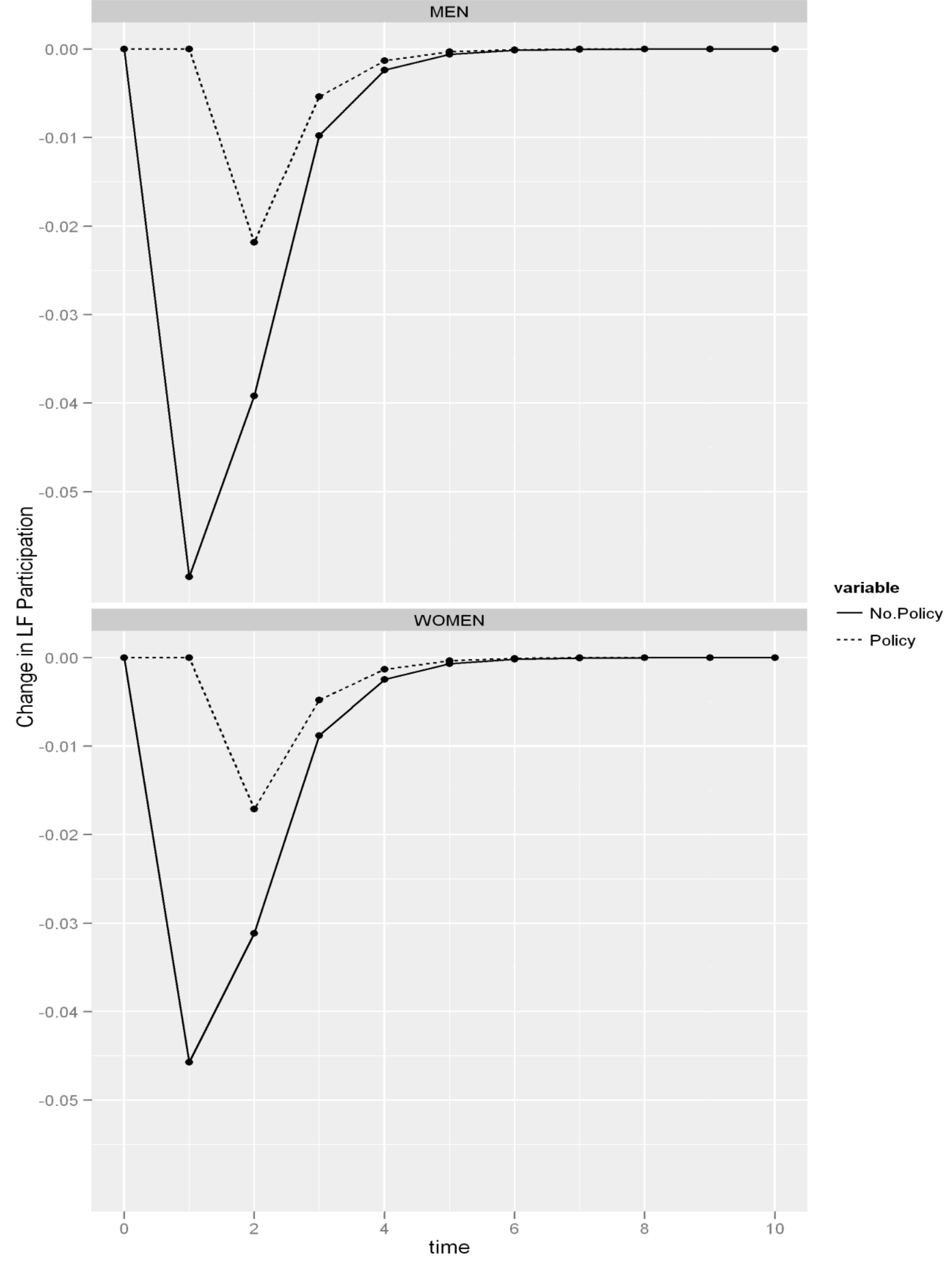


Figure 3 Labour Force Response to a Permanent Disability

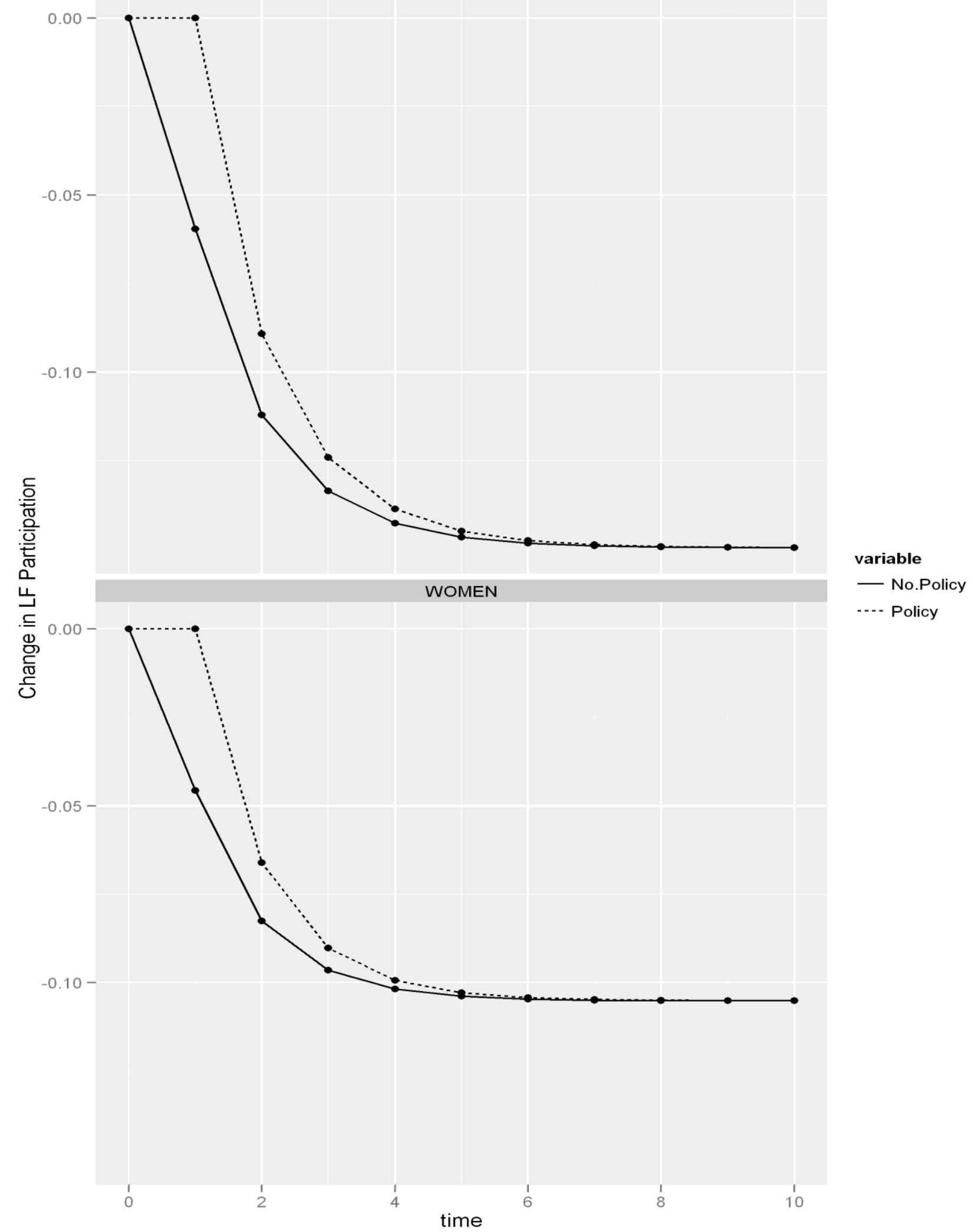


TABLE 8: DISABILITY MODEL RESULTS

\begin{tabular}{|c|c|c|}
\hline & MEN & WOMEN \\
\hline \multirow[t]{2}{*}{ resp } & $0.549 * * *$ & $0.636 * * *$ \\
\hline & $(0.0017)$ & $(0.0014)$ \\
\hline \multirow[t]{2}{*}{ arth } & $1.057 * * *$ & $0.969 * * *$ \\
\hline & $(0.0011)$ & $(0.0010)$ \\
\hline \multirow[t]{2}{*}{ bapr } & $0.953 * * *$ & $0.948 * * *$ \\
\hline & $(0.0009)$ & $(0.0009)$ \\
\hline \multirow[t]{2}{*}{ blpr } & $0.359 * * *$ & $0.233 * * *$ \\
\hline & $(0.0013)$ & $(0.0013)$ \\
\hline \multirow[t]{2}{*}{ mig } & $0.450 * * *$ & $0.453 * * *$ \\
\hline & $(0.0017)$ & $(0.0011)$ \\
\hline \multirow[t]{2}{*}{ diab } & $0.414 * * *$ & $0.361 * * *$ \\
\hline & $(0.0020)$ & $(0.0023)$ \\
\hline \multirow[t]{2}{*}{ hecon } & $1.180 * * *$ & $0.779 * * *$ \\
\hline & $(0.0019)$ & $(0.0022)$ \\
\hline \multirow[t]{2}{*}{ cancer } & $1.038 * * *$ & $0.685^{* * *}$ \\
\hline & $(0.0033)$ & $(0.0024)$ \\
\hline \multirow[t]{2}{*}{ vipro } & $0.545 * * *$ & $0.549 * * *$ \\
\hline & $(0.0028)$ & $(0.0021)$ \\
\hline \multirow[t]{2}{*}{ othercond } & $0.357 * * *$ & $0.357 * * *$ \\
\hline & $(0.0010)$ & $(0.0010)$ \\
\hline \multirow[t]{2}{*}{ BMI2034 } & $0.152 * * *$ & $0.131 * * *$ \\
\hline & $(0.0014)$ & $(0.0009)$ \\
\hline \multirow[t]{2}{*}{ age } & $0.499 * * *$ & $0.176 * * *$ \\
\hline & $(0.0046)$ & $(0.0044)$ \\
\hline \multirow[t]{2}{*}{ age 2} & $-0.0104 * * *$ & $0.0169 * * *$ \\
\hline & $(0.0004)$ & $(0.0004)$ \\
\hline \multirow[t]{2}{*}{ capincome } & $0.0159 * * *$ & $0.0847 * * *$ \\
\hline & $(0.0009)$ & $(0.0009)$ \\
\hline \multirow[t]{2}{*}{ ownhouse } & $0.0807 * * *$ & $0.0767 * * *$ \\
\hline & $(0.0013)$ & $(0.0013)$ \\
\hline \multirow[t]{2}{*}{ marr } & $-0.0535 * * *$ & $-0.195 * * *$ \\
\hline & $(0.0015)$ & $(0.0013)$ \\
\hline \multirow[t]{2}{*}{ univerdegree } & $-0.107 * * *$ & $-0.0853 * * *$ \\
\hline & $(0.0011)$ & $(0.0010)$ \\
\hline \multirow[t]{2}{*}{ white } & $0.0589 * * *$ & $0.240 * * *$ \\
\hline & $(0.0020)$ & $(0.0019)$ \\
\hline \multirow[t]{2}{*}{ immig } & $-0.412 * * *$ & $-0.229 * * *$ \\
\hline & $(0.0017)$ & $(0.0015)$ \\
\hline \multirow[t]{2}{*}{ Const. } & $-2.992 * * *$ & $-2.454 * * *$ \\
\hline & $(0.01)$ & (0.009) \\
\hline
\end{tabular}


Note : Estimates from a panel probit model of disability with random effects. Standard Errors are in parenthesis. $*^{* * * * * *}$ refer to significance at 10,5 and 1 percent respectively. The model is estimated using panel probit estimation with random effects. All models include time and regional dummies and the time averages of all time varying control variables. 


\section{REFERENCES}

Au, D. W. H., Crossley, T. F., Schellhorn, M., Oct. 2005. The effect of health changes and long-term health on the work activity of older Canadians. Health Economics 14 (10),999-1018.

Bound, J., Schoenbaum, M., Waidman, T., 1995. Race and Education Differences in Disability Status and Labor Force Participation. Journal of Human Resources 30, S227-S267.

Buckley, N., Denton, F., Robb, C., \& Spencer, B. (2006). Socio-economic influences on the health of older Canadians. Canadian Public Policy,32(1), 59-81.

Cai, L. (2010). The relationship between health and labour force participation : Evidence from a panel data simultaneous equation model. Labour Economics, 17(1), pp. 77-90.

Campolieti, M. 2001. Disability insurance and the labour force participation of older men and women in Canada. Canadian Public Policy. 2001 vol: 27 (2) pp. 179-194

Campolieti, M., 2002. Disability and the labor force participation of older men in Canada. Labour Economics 9 (3), 405-432.

Charles, Kerwin K. 2003. "The Longitudinal Structure of Earnings Losses among Work-Limited Disabled Workers." Journal of Human Resources 38(3):619-46.

Mok Wallace K.C., Meyer, B.D., Charles, K., Achen A.C. (2010) A Note on "The Longitudinal Structure of Earnings Losses among Work-Limited Disabled Workers" forthcoming in Journal of Human Resources

Galarneau, D., Radulescu, M., 2009. Employment among the disabled. Perspectives on Labour and Income 10 (5). Statistics Canada.

Gannon, B., 2005. A dynamic analysis of disability and labour force participation in Ireland1995 - 2000. Health Economics 14, 925-938.

Gruber, J., Dec. 2000. Disability Insurance Beneffts and Labor Supply. Journal of Political Economy 108 (6), 1162-1183.

Harkness, J., 1993. Labour force participation by disabled males in Canada. Canadian Journal of Economics vol. 26 (4) pp. 878-889.

Heckman, J. J., 1981. The Incidental Parameters Problem and the Problem of Initial Conditions in Estimating a Discrete Time-Discrete Data Stochastic Process and Some Monte Carlo Evidence. In: Structural Analysis of Discrete Data with Econometric Applications. London : MIT Press.

Hum, D., Simpson, W., 1996. Canadians with Disabilities and the Labour Market. Canadian Public Policy, 285-297.

Human Resources and Skills Development Canada. (2010) Federal Disability Report

Jongbloed, L. (2003) Disability policy in Canada: An overview. Journal of Disability Policy Studies, 13

(4) (2003), pp. 203-210 
Kapteyn, A., Smith, J. P., van Soest, A., 2008. Dynamics of work disability and pain. Journal of Health economics 27 (2), 496-509.

Maki, D. R., Jan. 1993. The Economic Implications of Disability Insurance in Canada. Journal of Labor Economics 11 (S1), S148.

Mundlak, Y., 1978. On the Pooling of Time Series and Cross Section Data. Econometrica 46 (1), 69-85.

OECD (2010). Sickness, Disability and Work. Breaking the barriers. A Synthesis of Findings across OECD Countries. Paris: OECD Publishing; 2010

Oguzoglu, U., 2010. Dynamics of Work Limitation and Work In Australia. Health Economics 19, 656669.

Oguzoglu, U. 2012. Is there a better measure of self-assessed disability?, Applied Economics Letters, vol. 19 (14), 1335-1338.

Stern, S., 1989. Measuring the Effect of Disability on Labor Force Participation. Journal of Human Resources 24 (3), 361-395.

Wooldridge, J. M., 2005. Simple solutions to the initial conditions problem in dynamic, non-linear panel data models with unobserved heterogeneity. Journal of Applied Econometrics 20 (1), 39-54 